Original Article $\quad$ www.pjkd.com.pk

\title{
Health Related Quality of Life Among Chronic Kidney Disease Patients Undergoing Hemodialysis in Pakistan.
}

\author{
Raheel Ahmed ${ }^{*}$, Tanveer Ahmed', Najm Ud Din', Syed Munib1* Inayat \\ Ur Rehman ${ }^{2}$, Abdul Haseeb ${ }^{1}$ \\ ${ }^{1}$ Department of Nephrology and Renal Transplantation, Institute of Kidney \\ Diseases Hayatabad Peshawar, Khyber Pakhtunkhwa, Pakistan. \\ ${ }^{2}$ Department of Pharmacy, Abdul Wali Khan University, Mardan, Khyber \\ Pakhtunkhwa, Pakistan.
}

\begin{abstract}
Background: Hemodialysis is a well-established replacement therapy for patient with end stage renal disease. But it has a great impact on the patient' s quality of life. Therefore, the purpose of this study is to identify the health-related quality of life of patients receiving hemodialysis.

Methods: A cross sectional single centered survey was carried out from March 2018 to June 2018 at Department of Nephrology, Institute of Kidney diseases, Peshawar in Pakistan. A 36 item KDQOL validated Urdu version was used to identify the quality of life of patients.

Results: A total of $\mathrm{n}=184$ patients having chronic kidney disease undergoing hemodialysis participated,of whom $63.6 \%$ were males and $57.1 \%$ patients were Pashtun. A multiple linear regression showed that patients having kidney disease caused due to hypertension had $45 \%$ higher kidney disease component summary (KDCS) score while 16\% higher physical component summary (PCS) score and 60\% higher mental component summary (MCS) score and were statistically significant. Similarly; Peshawari patients had 22\% lower PCS score as compared to other ethnic groups ; however, in MCS Peshawari patients had 16\% higher score and were statistically significant.

Conclusion: The patients have poor quality of life receiving hemodialysis therapy in all three domains like PCS, MCS and KDCS.
\end{abstract}

Keywords: Health Related Quality of life, Hemodialysis, Pakistan.

\author{
Corresponding Author \\ Dr. Syed Munib \\ Associate Professor \\ Chairman, Nephrology \& Renal Transplantation \\ Institute of Kidney Diseases Peshawar Pakistan. \\ Email: munibsyed@gmail.com
}

\section{Introduction}

Chronic kidney disease (CKD) has become a major public health issue worldwide and the incidence of chronic kidney disease is reported to be higher in South Asian populations as compared to European population. ${ }^{1,2}$ In Pakistan, CKD is on the rise; due to lack of a national registry to collect data of patients on dialysis. The elevated CKD incidence in Pakistan is considered to be the result of insufficient government support, high rates of diabetes and hypertension, faulty primary health care system and inadequate health education.

Chronic dialysis has a great impact on the patients' health-related quality of life (HRQOL), as it affects physical, social, psychological and emotional well-being of patients often leading to anxiety, depression, restless leg syndrome, post-dialysis fatigue and generalized weakness. ${ }^{4}$ In Pakistan, the QOL in patients with ESRD is assumed to be poorer compared to other countries because only $40 \%$ patients can access dialysis service, of which, 67\% receive inadequate dialysis (two dialysis/week) and are regarded as under-dialyzed. Patients with insufficient dialysis have poor QOL and lesser survival rate (1-2 years survival rate of 40.5\%). ${ }^{5}$ Moreover, compared to developed countries, there 
are very few formally trained nephrologists in Pakistan. ${ }^{6}$ The aim of this study was to measure HRQOL hemodialysis patients in a tertiary care center of Khyber Pakhtunkhwa province of Pakistan and to determine risk factor for poor HRQOL.

\section{Methods}

A cross-sectional, single center survey was conducted, patients were recruited from the Department of Nephrology, Institute of kidney disease (IKD) Peshawar, Pakistan from February 2018 to May 2018.

\section{Study population}

Inclusion criteria: Patients aged 18 years and above with CKD stage 5, both genders and undergoing hemodialysis at dialysis unit of Institute of kidney disease (IKD) Peshawar, were included in the study.

\section{Sample size}

The required sample size for this study was calculated by using a Cochrane sample size formula and based on $12.5 \%$ prevalence reported in previous study, 169 was the required sample size according to the formula used. ${ }^{7}$ However, to make it more precise and decrease the chances of error we included 184 patients in the present study.

\section{Data collection and instruments}

After providing their informed consent, patients were asked to complete the Urdu version of KDQOL $\mathrm{SF}^{\mathrm{TM}}$ version $1.3^{8}$

\section{Statistical analysis}

Data analysis was done using SPSS V.21. Patient' $\mathrm{s}$ demographic characteristics and items of the KDQOL were summarized using frequency distribution. PCS and MCS were calculated using KDQOL SF $\mathrm{SF}^{\mathrm{TM}} 1.3$ scoring program v.2.0. Multiple linear regressions were used to find the association of demographic characteristics such as dialysis per week, cause of CKD, gender, ethnicity, marital status, and education status. Beta coefficient $(\beta)$ was used to compare the strength of the effect of dependent variables over the independent variables. The higher the $\beta$ value, the stronger the relation. Statistical significance was set at p-value less than 0.05 .

\section{Results}

A total of $n=200$ patients were approached and $n=184$ patients participated in this research project and the response rate was $92 \%$, of whom (63.6\%) were males. Majority of the respondents (38.1\%) were among age group of 39 years or below; $(57.1 \%)$ were Pashtun and (85.3\%) were married as shown in table 1.

Patients having CKD caused by hypertension had $45 \%$ higher KDCS score as compared to others with $\beta=-0.451$ and CI 95\% [-5.629 - -3.228], similarly patients who were not illiterate had $34 \%$ higher KDCS score as compared to others, $\beta=0.341$ and CI 95\% [ 1.881 - 4.248] and both were statistically significant. The PCS score of patients having once a week dialysis and kidney disease caused by hypertension had 20\% and $16 \%$ higher PCS score as compared to others with $\beta=-0.202$ and CI 95\% [-6.657 - -1.572] and $\beta=-$ 0.169 and CI 95\% [-1.240 - -0.222], respectively. Peshawari patients had 22\% lower PCS score as compared to other ethnic groups with $\beta=0.224$ and CI 95\% [0.572 - 1.942] and among them patients who are not illiterate had 50\% higher PCS score as compared to others $\beta=0.508$ and CI 95\% [1.501 - 2.505] and were statistically significant. Patients having kidney disease caused by hypertension had 60\% higher MCS score as compared to other with $\beta=-0.609$ and CI 95\% [-4.048 - 2.809], while Peshawari patients had 16\% higher MCS score as compared to other ethnic groups with $\beta=-0.164$ and CI 95\% [-2.035 - 0.367] and were statistically significant, Table 2. The higher KDCS, PCS and MCS were indicative of better quality of life.

\section{Discussion}

In the present study, we found poor quality of life of patients receiving hemodialysis in all three domains such as PCS, MCS and KDCS. In our study it was observed that the mean score for KDCS was higher than PCS and MCS scores; which are similar to findings of another study done in India. ${ }^{9}$ 
HRQOL \& Hemodialysis

Table 1: Demographics characteristics of 184 maintenance hemodialysis patients.

\begin{tabular}{|c|c|c|c|}
\hline \multicolumn{2}{|l|}{ Variables } & \multirow{2}{*}{$\begin{array}{l}\text { Frequency }(\mathrm{n}) \\
117\end{array}$} & \multirow{2}{*}{$\begin{array}{l}\text { Percent \% } \\
63.6\end{array}$} \\
\hline Gender & Male & & \\
\hline & Female & 67 & 36.4 \\
\hline \multirow[t]{3}{*}{ Age } & 39 years or below & 70 & 38.0 \\
\hline & 40 to 49 years & 60 & 32.6 \\
\hline & 50 years or above & 54 & 29.3 \\
\hline \multirow[t]{4}{*}{ Ethnicity } & Peshawri & 36 & 19.6 \\
\hline & Pashtun & 105 & 57.1 \\
\hline & Punjabi & 35 & 19.0 \\
\hline & Afghani & 8 & 4.3 \\
\hline \multirow[t]{2}{*}{ Marital status } & Married & 157 & 85.3 \\
\hline & Single & 27 & 14.7 \\
\hline \multicolumn{2}{|c|}{ Highest level of education Illiterate } & 53 & 28.8 \\
\hline \multicolumn{2}{|c|}{ Primary Level } & 50 & 27.2 \\
\hline \multicolumn{2}{|c|}{ Secondary Level } & 45 & 24.5 \\
\hline \multicolumn{2}{|c|}{ Graduate Level } & 23 & 12.5 \\
\hline \multicolumn{2}{|c|}{ Postgraduate Level } & 13 & 7.1 \\
\hline Co-morbid conditions & Don't know & 28 & 15.2 \\
\hline \multicolumn{2}{|c|}{ Hypertension } & 62 & 33.7 \\
\hline \multicolumn{2}{|l|}{ Diabetes } & 69 & 37.5 \\
\hline & Polycystic kidney disease & 5 & 2.7 \\
\hline & Chronic glomerulonephritis & 20 & 10.9 \\
\hline \multirow[t]{5}{*}{ Monthly income } & Less than Rs. 30,000 & 136 & 73.9 \\
\hline & Rs. 30,000 - Rs. 50,000 & 42 & 22.8 \\
\hline & Rs. 51,000 - Rs. 75,000 & 3 & 1.6 \\
\hline & Rs. 75,000 - Rs. 100,000 & 2 & 1.1 \\
\hline & Rs. 100,000 and above & 1 & 0.5 \\
\hline \multirow[t]{2}{*}{ Dialysis Per week } & Once per week & 11 & 6.0 \\
\hline & Twice per week & 173 & 94.0 \\
\hline
\end{tabular}

The current study reported significantly poorer QOL in the presence of hypertension compared to other comorbidities (especially diabetes), measured as KDCS, PCS and MCS, respectively. This higher difference may be due to higher kidney disease burden in the presence of diabetes, because diabetes as reported in these studies was the leading cause of CKD. Our study findings are aligned with the finding by others also. ${ }^{9-11}$

Similarly, we found higher QOL among educated patients in all three domains (KDCS, PCS and MCS) because educated patients can easily adopt to guidelines and precautions from their healthcare team. Similar results were reported by a recent study conducted in Pakistan. ${ }^{12}$ Ethnicity is another factor affecting the quality of life of hemodialysis patients. Our study reported, 16\% higher QOL under MCS among Peshawari patients while 22\% lower physical health compared to other ethnic groups. The lower MCS score among other ethnic groups except Peshawari may be due to the differences in patients' beliefs, disease perception, and understanding of treatment modalities which directly affect psychological well-being of the patient. t.14 $^{14}$ 
Table 2: Multiple linear regression analysis of kidney disease component summary, physical component summary and mental component summary among 184 maintenance hemodialysis patients.

\begin{tabular}{|c|c|c|c|c|c|c|c|c|c|}
\hline \multirow{2}{*}{ Characteristic } & \multicolumn{3}{|l|}{ KDCS } & \multicolumn{3}{|l|}{ PCS } & \multicolumn{3}{|l|}{ MCS } \\
\hline & $\beta$ & $\mathrm{Cl}[95 \%]$ & p-value & $\beta$ & $\mathrm{Cl}$ [95\%] & $\begin{array}{l}\mathrm{p}- \\
\text { value }\end{array}$ & $\beta$ & $\mathrm{Cl}$ [95\%] & $p$-value \\
\hline $\begin{array}{l}\text { Dialysis/Week: } \\
\text { once }\end{array}$ & -0.086 & $\begin{array}{l}-9.992 \\
2.000\end{array}$ & 0.190 & -0.202 & $\begin{array}{l}-6.657 ; \\
-1.572\end{array}$ & 0.002 & -0.088 & $\begin{array}{l}-5.423 \\
0.763\end{array}$ & 0.139 \\
\hline $\begin{array}{l}\text { CKD Cause: } \\
\text { Hypertension }\end{array}$ & -0.451 & $\begin{array}{l}-5.629 \\
-3.228\end{array}$ & $<0.001$ & -0.169 & $\begin{array}{l}-1.240 \\
-0.222\end{array}$ & 0.005 & -0.609 & $\begin{array}{l}-4.048 \\
-2.809\end{array}$ & $<0.001$ \\
\hline Gender: Male & 0.063 & $\begin{array}{l}-1.520 \\
4.404\end{array}$ & 0.338 & -0.096 & $\begin{array}{l}-2.214 \\
0.298\end{array}$ & 0.134 & 0.120 & $\begin{array}{l}0.042 ; \\
3.098]\end{array}$ & 0.044 \\
\hline $\begin{array}{l}\text { Ethnicity: } \\
\text { Peshawari }\end{array}$ & -0.015 & $\begin{array}{l}-1.812 \\
1.421\end{array}$ & 0.812 & 0.224 & $\begin{array}{l}0.572 ; \\
1.942\end{array}$ & $<0.001$ & -0.164 & $\begin{array}{l}-2.035 ; \\
-0.367]\end{array}$ & 0.005 \\
\hline $\begin{array}{l}\text { Marital status: } \\
\text { Married }\end{array}$ & 0.100 & $\begin{array}{l}-0.835 \\
7.046\end{array}$ & 0.122 & -0.120 & $\begin{array}{l}-3.307 \\
0.034\end{array}$ & 0.055 & 0.020 & $\begin{array}{l}-1.668 \\
2.397\end{array}$ & 0.724 \\
\hline $\begin{array}{l}\text { Education } \\
\text { status: } \\
\text { Illiterate }\end{array}$ & 0.341 & $\begin{array}{l}1.881 ; \\
4.248\end{array}$ & $<0.001$ & 0.508 & $\begin{array}{l}1.501 ; \\
2.505\end{array}$ & $<0.001$ & 0.201 & $\begin{array}{l}0.425 \\
1.646]\end{array}$ & 0.001 \\
\hline
\end{tabular}

According to the demographic characteristics of the study population, kidney disease was common in younger patients, which are inconsistent with a study by Yang et al. ${ }^{15}$ Similar points were highlighted by other authors in Pakistan about young age patients suffering from CKD and multiple factors were considered to be accountable for poor outcomes during dialysis including late referral, malnutrition, anemia, inadequate dialysis, and the lack of availability of qualified nephrologists at dialysis unit. ${ }^{16-19}$ Males were more exposed to kidney disease and hemodialysis verses females as reported by studies. ${ }^{10,20}$ The mental component score of males were $12 \%$ higher verses females and this difference may be due to poor access of women to health care in our culture especially in pashtun society.

Overall, patients on hemodialysis in our study were observed to have poor quality of life and the possible reason for this may be inadequate dialysis, lack of knowledge and poor literacy status of patients, short duration of dialysis session, less number of nephrologist in dialysis unit, economic burden and limited resources provided by the government for the health budget.

There are some potential limitations of the study; we conducted this study in a single center, instead multicenter studies are needed in order to make the results more generalizable. Moreover, we did not include an important aspect of HRQOL estimate of sexual function of the study participants due to social barriers.

\section{Conclusion}

The present study reported poor quality of life in hemodialysis patients in all three domains such as physical component summary, mental component summary and kidney disease component summary. Therefore, proper attentions are needed to improve the QOL of hemodialysis patients by identifying and removing factors which impair the QOL of patients.

Conflict of Interest: None declared

\section{References}

1. A Trehan, J Winterbottom, B Lane, R Foley, M Venning, R Coward et al. End-stage renal disease in Indo-Asians in the North-West of England. QJM2003;7(96):499504. https://doi.org/10.1093/qjmed/hcg088 


\section{HRQOL \& Hemodialysis}

2. Fischbacher CM, Bhopal R, Rutter MK, Unwin NC, Marshall SM, White M., et al., Microalbuminuria is more frequent in South Asian than in European origin populations: a comparative study in Newcastle, UK. Diabet Med. 2003;20(1):31-6. doi: 10.1046/j.1464-5491.2003.00822.x.

3. Ullah K, Butt G, Masroor I, Kanwal K, Kifayat F. Epidemiology of chronic kidney disease in a Pakistani population. Saudi J Kidney Dis Transpl. 2015 Nov;26(6):1307-10. doi: 10.4103/13192442.168694.

4. Finkelstein FO, Wuerth D, Finkelstein SH. Health related quality of life and the CKD patient: challenges for the nephrology community. Kidney Int. 2009 Nov;76(9):946-52. doi: 10.1038/ki.2009.307.

5. Anees M, Hameed F, Mumtaz A, Ibrahim M, Saeed Khan MN. Dialysis-related factors affecting quality of life in patients on hemodialysis. Iran J Kidney Dis. 2011 Jan;5(1):9-14.

6. Anees M, Malik MR, Abbasi T, Nasir Z, Hussain Y, Ibrahim M. Demographic factors affecting quality of life of hemodialysis patients - Lahore, Pakistan. Pak J Med Sci. 2014 Sep;30(5):1123-7. doi: 10.12669/pjms.305.5239.

7. Jessani, S., Bux, R. \& Jafar, T.H. Prevalence, determinants, and management of chronic kidney disease in Karachi, Pakistan - a community based cross-sectional study. BMC Nephrol 15, 90 (2014). https://doi.org/10.1186/1471-2369-15-90

8. Anees M, Ibrahim M, Imtiaz M, Batool S, Elahi I, Malik MR. Translation, Validation and Reliability of the Kidney Diseases Quality of Life-Short Form (KDQOL-SF Form) Tool in Urdu. J Coll Phy Surg Pak. 2016;26(8):651-4.

9. S.A. Nayana, T. Balasubramanian, P.M. Nathaliya, P. Nimsha Hussain, K.T. Mohammed Salim, P. Muhammed Lubab, A cross sectional study on assessment of health related quality of life among end stage renal disease patients undergoing hemodialysis, Clinical Epidemiology and Global Health 2017;3(5):148-153, ISSN 2213-3984, https://doi.org/10.1016/j.cegh.2016.08.005

10. Abraham S, Venu A, Ramachandran A, Chandran PM, Raman S. Assessment of quality of life in patients on hemodialysis and the impact of counseling. Saudi J Kidney Dis Transpl. 2012 Sep;23(5):953-7. doi: 10.4103/1319-2442.100875.

11. Hussain H, Apetrii M, Covic A. Health-related quality of life in patients with chronic kidney disease. Exp Rev Pharm Outcome Res. 2021;21:43 - 54.

12. Anees M, Batool S, Imtiaz M, Ibrahim M. Socio-economic factors affecting quality of life of Hemodialysis patients and its effects on mortality. Pak J Med Sci. 2018;34(4):811-816. doi: https://doi.org/10.12669/pjms.344.15284

13. Chan R., Brooks R., Erlich J., Gallagher M., Snelling P., Chow J., et al. How do clinical and psychological variables relate to quality of life in end-stage renal disease? Validating a proximal distal model. Qual Life Res 2014;23:677 - 686. https://doi.org/10.1007/s11136-013-0499-1

14. Theofilou P. Quality of life and mental health in hemodialysis and peritoneal dialysis patients: the role of health beliefs. Int Urol Nephrol. 2012;44(1):245-53. doi: 10.1007/s11255-011-9975-0.

15. Yang F, Griva K, Lau T, Vathsala A, Lee E, Ng HJ, et al. Health-related quality of life of Asian patients with end-stage renal disease (ESRD) in Singapore. Qual Life Res. 2015 Sep;24(9):2163-71. doi: 10.1007/s11136-015-0964-0.

16. Shafi ST, Haq RU, Shafi T. Adequacy of Hemodialysis \& Laboratory parameters in patients at Shaikh Zayed Medical Complex Hemodialysis Center, Lahore. Proceed SZPGMI 2003:17(1):7-12.

17. Muhammad Rafiq Zaki, Abbas Ghazanfar, Shahid Hussain, Farrakh Ahmad Khan, Presentations, etiology and outcome of patients with Chronic Renal Failure admitted at Urology Department, Mayo Hospital Lahore - A retrospective analysis of 1257 patients over a period of 10 years. Ann King Ed Med Uni. 2003;1(9):58-61

18. Anees M, Mumtaz A, Nazir M, Ibrahim M, Rizwan SM, Kausar T. Referral pattern fof hemodialysis patients to nephrologists. J Coll Phy Surg Pak. 2007 Nov;17(11):671-4.

19. Anees M, Ibrahim M. Anemia and hypoalbuminemia at initiation of hemodialysis as risk factor for survival of dialysis patients. J Coll Physicians Surg Pak. 2009 Dec;19(12):776-80. PMID: 20042156.

20. Sathvik BS, Parthasarathi G, Narahari MG, Gurudev KC. An assessment of the quality of life in hemodialysis patients using the WHOQOL-BREF questionnaire. Indian J Nephrol. 2008 Oct;18(4):141-9. doi: 10.4103/0971-4065.45288 